\title{
THE INCIDENCE OF LIVE BACTERIA IN BILE, GALLBLADDER INNER WALL AND GALLSTONES IN GALLSTONE DISEASE- A SEARCH
}

\author{
Partha Sarathi Mandal', Kumar Dheeraj2, Saurabh Das ${ }^{3}$, Probhas Kumar Sarkatr ${ }^{4}$, Nupur Pal 5
}

1Postgraduate Trainee, Department of General Surgery, IPGME and $R$.

2 Postgraduate Trainee, Department of General Surgery, IPGME and $R$.

${ }^{3}$ Assistant Professor, Department of General Surgery, IPGME and $R$.

${ }^{4}$ Professor, Department of General Surgery, IPGME and R.

${ }^{5}$ Assistant Professor, Department of Microbiology, IPGME and $R$.

\section{ABSTRACT}

\section{BACKGROUND}

Gallstone disease and associated cholecystectomy has taken enormous portion of all surgical procedures in the world, as it is the most frequent surgical procedure practiced in any part of the world. The myth of fat, fertile, female of forty has long been busted as also the story of "Typhoid Mary." As gallstones are now seen in all age groups, in both sexes and in all corners of the globe, most frequently asked question confronted by the surgeons in the clinic from the patients is how these stones occur? Various theories of stone formation have been postulated, but the role of bacteria in gallstone formation is still mysterious.

In this study, we are trying to find out the incidence of live bacteria in bile, gallbladder inner wall and gallstones in gallstone disease.

\section{MATERIALS AND METHODS}

This is a short-term, prospective, observational study. Conveniently selected 50 patients with Gallstone disease who underwent cholecystectomy in our surgical unit of IPGME and R and SSKM Hospital during May 2015 to October 2016 were studied for existence of infectious foci in the form of live bacterial pathogen as cultured from bile, gallbladder inner wall and gallstone.

\section{RESULTS}

Majority of the patients were female [88\%] with mean age of 40.5 years. Most of the patients had cholesterol stones (35 cases), followed by pigment stones (10 cases) and mixed stones ( 5 cases) in the gallbladder. Bile culture was positive in 6 patients, gallbladder inner wall culture was positive in 7 patients and gallstones culture was positive in 4 patients rendering 12 patients having culture positive in either source. E. coli and Klebsiella spp. (in 3 patients each) were the predominant organisms seen in these cultures. Out of 35 patients with cholesterol stones, 3 patients had positive growth; and out of 10 patients with pigment type of stones, 4 patients had positive growth; and all 5 patients with mixed type of stones showed positive bacterial growth in at least one sample. The mixed stones had statistically higher incidence of culture positivity than cholesterol and pigment stones $\left(\chi^{2}=21.8\right.$, $\mathrm{p}<0.001)$. Males had significantly higher association with live bacteria than female $\left(\chi^{2}=13.16, p=0.002\right)$. HPE report of specimen of gallbladder showed chronic cholecystitis in all 50 patients.

\section{CONCLUSION}

12 patients being positive for bacterial infection is significantly high as in general consensus bile and gallbladder, both are sterile. Higher incidence of positive culture was found in patients with mixed stones than cholesterol and pigment stones, though overall incidence of cholesterol stone was maximal. Type of stone is single deterministic factor in the incidence of bacterial culture positivity. Since different gram negative bacterial organisms are more co-existent in gallstones, there might be a new consensus required for antibacterial protocol in the management of gall stone disease in a given area.

\section{KEYWORDS}

Gallstone Disease, Bile Culture, Gallbladder Inner Wall Culture, Gallstone Culture.

HOW TO CITE THIS ARTICLE: Mandal PS, Dheeraj K, Das S, et al. The incidence of live bacteria in bile, gallbladder inner wall and gallstones in gallstone disease- a search. J. Evolution Med. Dent. Sci. 2017;6(44):3439-3445, DOI: 10.14260/Jemds/2017/745

\section{BACKGROUND}

Gallstone disease is one of the most prevalent gastrointestinal diseases with a substantial burden to healthcare systems. ${ }^{1}$ In the United States, there are more than 500,000 cholecystectomies, the total cost of which exceeds 5 billion dollars. ${ }^{2}$

Financial or Other, Competing Interest: None.

Submission 28-04-2017, Peer Review 21-05-2017,

Acceptance 27-05-2017, Published 01-06-2017.

Corresponding Author:

Dr. Partha Sarathi Mandal,

Royal Arcade, $4^{\text {th }}$ Floor,

Near Pragati Sangha Club,

P. O-Baruipur-700144.

E-mail: hemendra_partha@yahoo.co.in

DOI: $10.14260 /$ jemds $/ 2017 / 745$
The prevalence of gallstone disease varies widely by region. In Western countries, the prevalence of gallstone disease reportedly ranges from approximately $7.9 \%$ in men to $16.6 \%$ in women. ${ }^{3}$ In Asians, it ranges from approximately $3 \%$ to $15 \%$; is nearly non-existent (less than $5 \%$ ) in Africans ${ }^{4,5}$ and ranges from $4.21 \%$ to $11 \%$ in China. ${ }^{6}$ In India also there is a huge variance in prevalence, varying from 2 $29 \%$ in different studies [Prakash A. C. (2016). Prevalence and Management of Cholelithiasis in East India [Abstract]. IOSR-JDMS, 15(12), 34-37], concluding North Indian population has seven times higher risk of developing gall stones. [Malhotra S. L. (1968). Epidemiological study of cholelithiasis among railroad workers in India with special reference to causation. Gut, 9(3), 290-295].

Gallstones can stay silent or be minimally symptomatic and be discovered only as incidental findings or may manifest 
themselves with dramatic clinical features of acute cholecystitis and obstructive jaundice. They may be located in any part of the biliary tract, but are primarily found in gallbladder and less often in the common bile duct or intrahepatic ductal system. Once gallstones are discovered, they may grow, shrink or remain the same size for years. Additional stones may form and existing stones may dissolve or be passed. Gas can appear within gallstones on radiography and disappear later. The radiographic lucency changes with time. All these phenomena, known to those who follow their patients over years and decades indicate that the gallstone structure and composition can fluctuate and that the gallstones do not appear and remain as a final product, but rather are in a continuous process of growth, dissolution and remodelling.

Despite these well documented observations of dynamic structural changes in the development of gallstones, gallstones are traditionally arbitrarily divided at the time of cholecystectomy according to their chemical composition into three main groups: cholesterol (more than $70 \%$ cholesterol), brown pigment gallstones (less than 30\% cholesterol) and black pigment gallstones (nearly no cholesterol). Other categories of gallstones (to which most stones belong) are described as composite, combined, complex or mixed.

The pathogenesis of gallstones is complex. Gallstone formation appears to be complex trait influenced by genes and environment, and their interaction. ${ }^{7}$ Genetic effects accounts for $25 \%$, shared environmental effects for $13 \%$ and unique environmental effects for $62 \%$ of the liability. ${ }^{8}$

Among the important environmental factors in the pathogenesis of gallstone, infective factor seem to be a major cause of formation of gallstones. Moynihan's aphorism "Gallstone is a tombstone erected in the memory of the organism within it," suggests bacteria inside gallstone have thought to be dead. ${ }^{9}$ Yet calculi spilled at laparoscopic cholecystectomy cause a variety of complications, ${ }^{10}$ e.g. intraperitoneal abscesses, intraperitoneal granuloma, wound infection, etc. Experimental studies have also confirmed that implantation of human gallstones in the peritoneal cavity of rat, rabbit and dog produces intraperitoneal abscesses, sinuses and adhesions, $10,11,12$ which states that gallstone is a dynamic viable home of bacteria rather than a tomb.

Evidence in favour of infection includes isolation of E. coli, Klebsiella, streptococcus from the gallbladder and from the centre of gallstones. This was more common in brown stones rather than cholesterol stones. ${ }^{13}$ These bacteria reach the gallbladder from infective focus in the gut or elsewhere in the body via blood stream and lymphatics.

Brown pigment gallstones occur as a result of infection. Bacterial DNA is present in all brown pigment stones, but only occasionally in black pigment stones or stones with a high cholesterol content ( $70 \%$ - 95\%). ${ }^{14}$

With the above background, this study was aimed to find out the prevalence of live bacteria in samples of gallbladder wall, bile and gall stone itself collected during the operative procedure and to find out the bacteriological profile of such infections in relation to type of gallstones. Also, the study was directed to find out the role of these pathological organisms in different gall stone formation.

\section{MATERIALS AND METHODS}

\section{Study Design}

This short-term prospective observational study was carried out in Department of General Surgery, IPGME and R, SSKM Hospital, Kolkata on a total of conveniently selected 50 cases who had proved gallstone disease (Age group between 15 to 70 years). The cases were selected conveniently, who were admitted with gallstone disease under care of our surgical unit for surgical intervention in the Department of General Surgery, IPGME and R, SSKM Hospital from May 2015 to October 2016. The sample size as 50 was taken, as this was a short-term study during my postgraduate trainee period and due to limited hospital resources.

To avoid spurious result, we excluded patients with isolated choledocholithiasis, gallbladder mass or growth and those who underwent emergency cholecystectomy and those who were preoperatively on antibiotics from our study.

The identity of the cases was kept confidential and ethical permission was taken from Institutional Ethics Committee, IPGME and R, SSKM Hospital.

\section{Collection of Pathological Samples}

a. Bile- Bile was aspirated from the gallbladder of the patient who underwent open cholecystectomy using a sterile syringe $(10 \mathrm{~mL})$. In case of Laparoscopic cholecystectomy, bile was collected by an aspirator. The collected bile was immediately sent to laboratory for culture.

b. Gallstones- After cholecystectomy, gallbladder was cut open and the largest stone was crushed in very small pieces and transferred to sterile culture bottle containing normal saline and immediately transferred to laboratory for stone culture. Retrieved stones were divided into three groups based on the morphology of gallstones.

1. Whitish to pale yellow as cholesterol stones.

2. Black to blackish brown as pigment stones.

3. Yellow brown and greenish white as mixed stones.

c. Gallbladder Inner Wall- A small portion of inner wall from gallbladder body was taken into a sterile culture bottle containing normal saline and immediately transferred to laboratory for culture.

d. Gallbladder was sent for histopathological examination to confirm diagnosis.

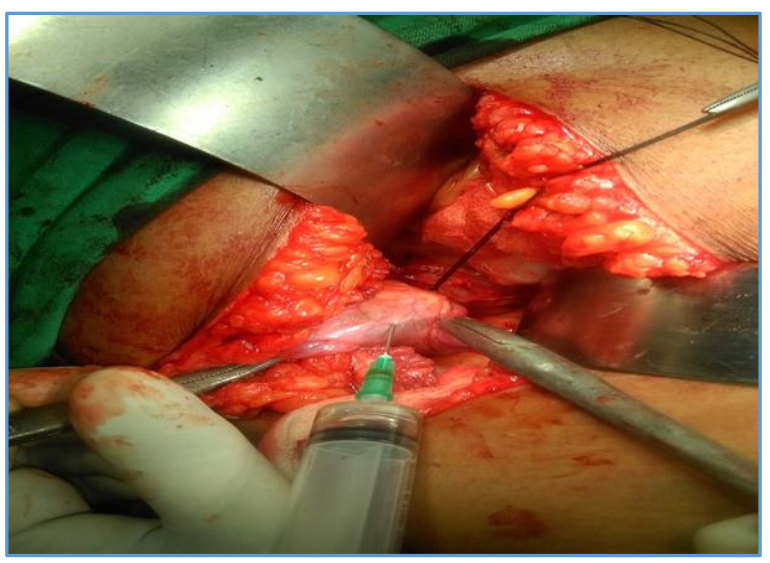

Figure 1. Collection of Sample of Bile for Culture during Open Cholecystectomy 


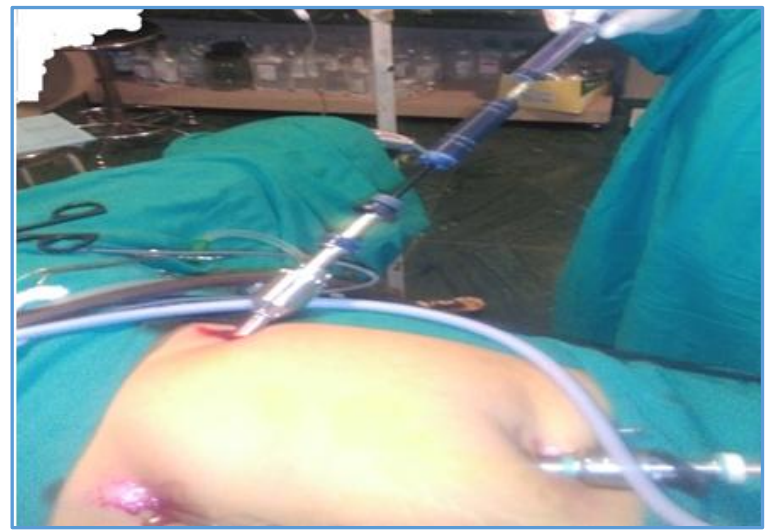

Figure 2A

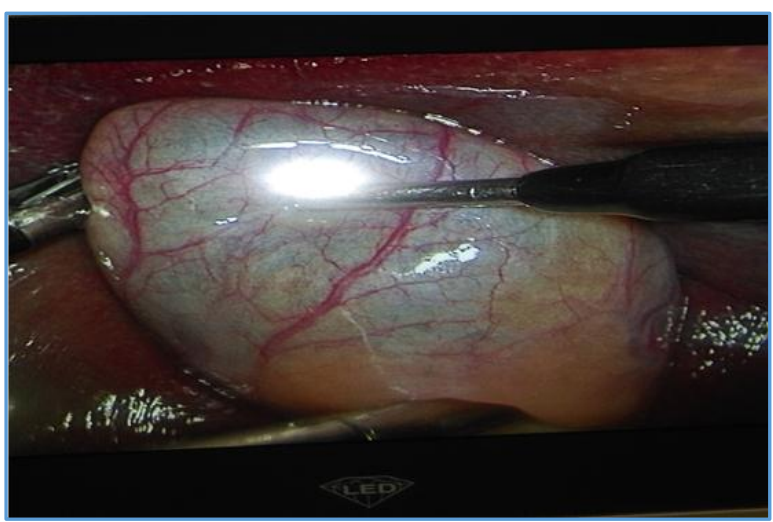

Figure $2 B$

Figure 2A. 2B. Collection of Sample of Bile for Culture during Laparoscopic Cholecystectomy

\section{Culture Technique}

As done in Department of Microbiology, IPGME and R, SSKM Hospital, Kolkata, all three samples were incubated in sterile manner by inoculating loop in MacConkey agar and blood agar. All plates were incubated at $37^{\circ} \mathrm{C}$ for $24 \mathrm{hrs}$. under aerobic condition. All the suspected isolates were further subcultured on nutrient agar plate for identification by Gram's staining, biochemical tests.

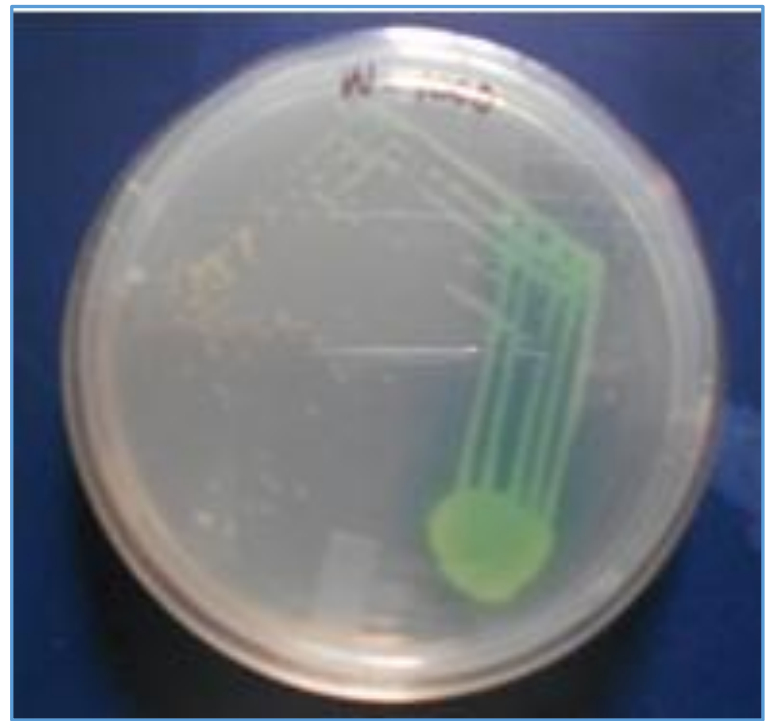

Figure 3. Growth of Pseudomonas aeruginosa showing Characteristic Pigmentation on Nutrient Agar

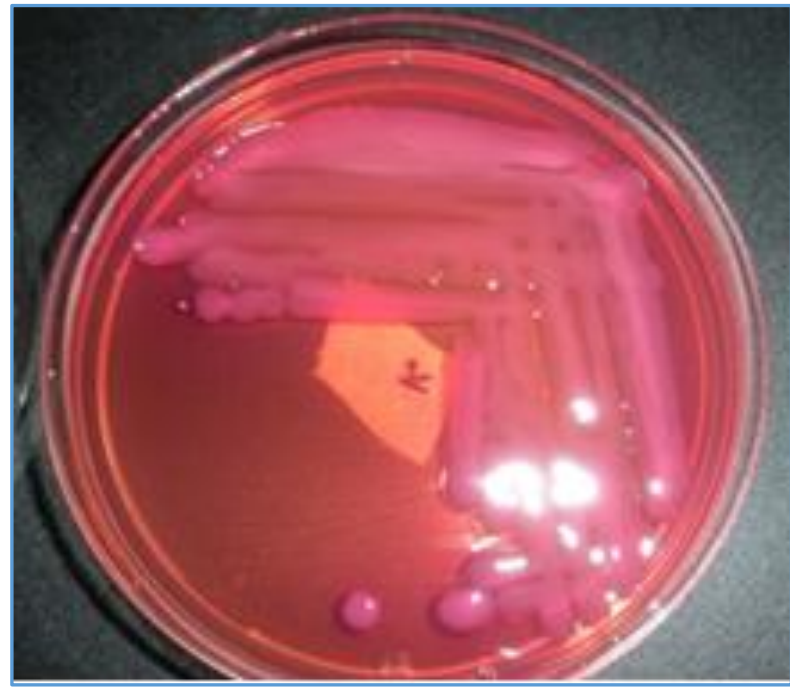

Figure 4. Growth of Klebsiella pneumonia on MacConkey Agar

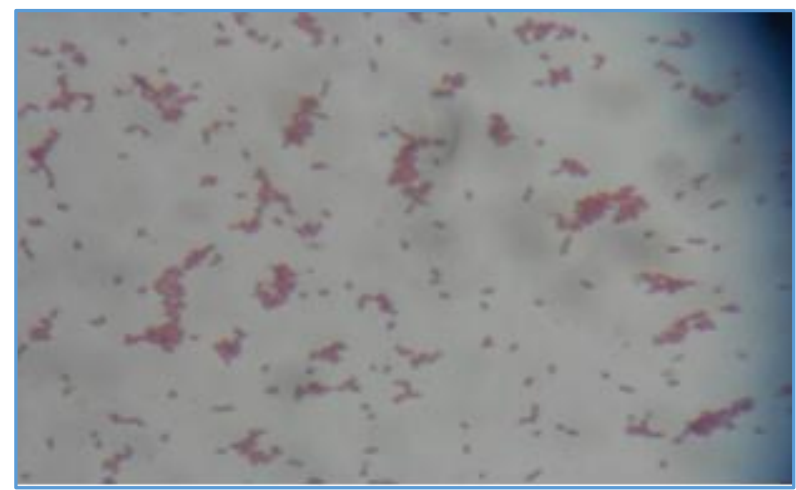

Figure 5. Gram's Staining showing Gram Negative Bacilli

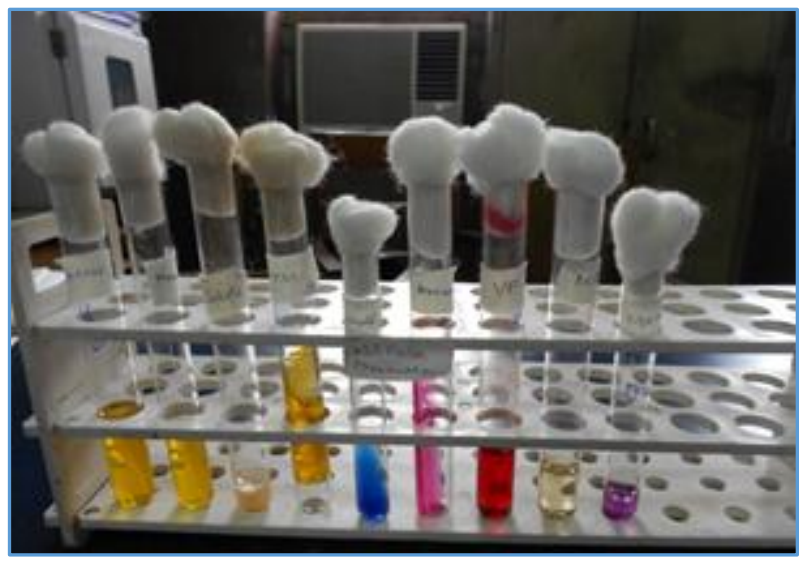

Figure 6. Biochemical Tests for Identification of Klebsiella pneumonia

\section{Statistical Analysis}

For statistical analysis data were entered into a Microsoft excel spreadsheet and then analysed by SPSS 20.0.1. Data had been summarized as mean and standard deviation for numerical variables and count and percentages for categorical variables. Z-test (Standard Normal Deviate) was used to test the significant difference of proportions. Association was compared by Chi-square test or Fisher's exact test as appropriate; $\mathrm{p}$ - value $\leq 0.05$ was considered as statistically significant. 


\section{RESULTS}

As per Table 1, in this study it was found that proportion of female $(88.0 \%)$ was significantly higher than male $(12.0 \%)$; ( $p<0.0001)$. Most patients had symptoms of biliary colic, flatulent dyspepsia and nausea and/or vomiting. Test of proportion showed that no history of jaundice was significantly higher $(\mathrm{p}<0.0001)$. No patient had fever with rigor. No patient had history of previous biliary surgery and infection (including typhoid). Most patients had non-palpable liver and non-palpable gallbladder. No patient had positive Murphy's sign.

As per Table 2, $31(62.0 \%)$ patients had multiple gallstones and $19(38.0 \%)$ patients had single gallstone as per USG of upper abdomen report; 28 (56.0\%) patients underwent laparoscopic cholecystectomy, 21 (42\%) patients underwent open cholecystectomy and 1 (2.0\%) patient underwent open cholecystectomy with CBD exploration with T-tube insertion. Percentage of operative procedure was not statistically significant $(\mathrm{p}=0.16152) ; 35(70.0 \%)$ patients had cholesterol type of gallstones, $10(20.0 \%)$ patients had pigment type of gallstones and $5(10.0 \%)$ patients had mixed type of gallstones. Test of proportion found that cholesterol type of gallstones was significantly higher than others ( $\mathrm{p}<$ 0.0001). In bile culture, $2(4.0 \%)$ patients had growth of Klebsiella spp. and $1(2.0 \%)$ patient showed Citrobacter koseri, E. coli, Pseudomonas spp. and Staph. aureus (MRSA) each; $44(88.0 \%)$ patients had no growth in bile culture. In gallbladder inner wall culture, $1(2.0 \%)$ patient had growth of Enterobacter spp., 3 (6.0\%) patients had E. coli and Klebsiella spp. each; 43 (86.0\%) patients had no growth in gallbladder inner wall culture. In culture of gallstones, $2(4.0 \%)$ patients had growth of Klebsiella spp., 1 (2.0\%) patient had Citrobacter koseri and Pseudomonas spp. each; 46 (92.0\%) patients had no growth in gallstone culture. In this study 12 $(24.0 \%)$ had positive growth in at least one sample, whereas $38(76.0 \%)$ had no growth and this proportion was significantly higher $(\mathrm{p}<0.0001)$.

In Table 3, association of growth or no growth of bacteria in at least one sample with type of gallstones and sex has been shown. Out of $35(70.0 \%)$ patients with cholesterol type of stones, $3(6.0 \%)$ patients had positive growth. All 5 $(10.0 \%)$ patients with mixed type of stones showed positive bacterial growth in at least one sample and this proportion was statistically significant $(\mathrm{p}=0.0015)$. And out of 10 $(20.0 \%)$ patients with pigment type of stones, $4(8.0 \%)$ patients had positive growth in at least one sample. The mixed stones have statistically higher incidence of culture positivity than cholesterol and pigment stones $\left(\chi^{2}=21.8, p<\right.$ 0.001). In this study, out of 44 female patients, 37 (74.0\%) patients had no growth in any sample and 7 (14.0\%) patients had bacterial growth in at least one sample. Again interestingly, out of 6 male patients $1(2.0 \%)$ patient had no growth and $5(10.0 \%)$ patients had growth in at least one sample- this proportion was statistically significant $(\mathrm{p}=$ 0.02088). Males have significantly higher association with live bacteria than female $\left(\chi^{2}=13.16, p=0.002\right)$.

In our study, histopathological report of specimen of gallbladder showed chronic cholecystitis in all 50 patients.

\begin{tabular}{|c|c|c|c|c|c|}
\hline & & No. & $\%$ & $\begin{array}{c}\mathrm{Z} \\
\text { Score } \\
\end{array}$ & $\begin{array}{c}P \\
\text { Value }\end{array}$ \\
\hline \multirow{6}{*}{$\begin{array}{c}\text { Age } \\
\text { (Years) }\end{array}$} & $\leq 20$ & 3 & $6.0 \%$ & \multirow{6}{*}{0.456} & \multirow{6}{*}{0.64552} \\
\hline & $21-30$ & 12 & $24.0 \%$ & & \\
\hline & $31-40$ & 14 & $28.0 \%$ & & \\
\hline & $41-50$ & 10 & $20.0 \%$ & & \\
\hline & $51-60$ & 8 & $16.0 \%$ & & \\
\hline & $61-70$ & 3 & $6.0 \%$ & & \\
\hline \multirow{2}{*}{ Sex } & Female & 44 & $88.0 \%$ & \multirow{2}{*}{7.6} & \multirow{2}{*}{$<0.0001$} \\
\hline & Male & 6 & $12.0 \%$ & & \\
\hline \multirow{2}{*}{ Biliary Colic } & Negative & 1 & $2.0 \%$ & \multirow{2}{*}{9.6} & \multirow{2}{*}{$<0.0001$} \\
\hline & Positive & 49 & $98.0 \%$ & & \\
\hline \multirow{2}{*}{ Jaundice } & Negative & 49 & $98.0 \%$ & \multirow{2}{*}{9.6} & \multirow{2}{*}{$<0.0001$} \\
\hline & Positive & 1 & $2.0 \%$ & & \\
\hline \multirow{2}{*}{$\begin{array}{l}\text { Fever with } \\
\text { Rigor }\end{array}$} & Negative & 50 & $100.0 \%$ & \multirow{2}{*}{ NA } & \multirow{2}{*}{ NA } \\
\hline & Positive & 0 & $0.0 \%$ & & \\
\hline \multirow{2}{*}{$\begin{array}{c}\text { Flatulent } \\
\text { Dyspepsia }\end{array}$} & Negative & 8 & $16.0 \%$ & \multirow{2}{*}{6.8} & \multirow{2}{*}{$<0.0001$} \\
\hline & Positive & 42 & $84.0 \%$ & & \\
\hline \multirow{2}{*}{$\begin{array}{c}\text { Nausea and } \\
\text { Vomiting }\end{array}$} & \begin{tabular}{|l|} 
Negative \\
\end{tabular} & 12 & $24.0 \%$ & \multirow{2}{*}{5.2} & \multirow{2}{*}{$<0.0001$} \\
\hline & Positive & 38 & $76.0 \%$ & & \\
\hline \multirow{2}{*}{\begin{tabular}{|c|} 
Previous Biliary \\
Surgery \\
\end{tabular}} & Negative & 50 & $100.0 \%$ & \multirow{2}{*}{ NA } & \multirow{2}{*}{ NA } \\
\hline & Positive & 0 & $0.0 \%$ & & \\
\hline \multirow{2}{*}{$\begin{array}{c}\text { Previous } \\
\text { Infection } \\
\text { (Including } \\
\text { Typhoid) }\end{array}$} & Negative & 50 & $100.0 \%$ & \multirow[b]{2}{*}{ NA } & \multirow[b]{2}{*}{ NA } \\
\hline & Positive & 0 & $0.0 \%$ & & \\
\hline \multirow[t]{2}{*}{ Liver } & $\begin{array}{c}\text { Not } \\
\text { Palpable } \\
\end{array}$ & 46 & $92.0 \%$ & \multirow[t]{2}{*}{8.4} & \multirow[t]{2}{*}{$<0.0001$} \\
\hline & Palpable & 4 & $8.0 \%$ & & \\
\hline \multirow[t]{2}{*}{ Gallbladder } & $\begin{array}{c}\text { Not } \\
\text { Palpable }\end{array}$ & 49 & $98.0 \%$ & \multirow[t]{2}{*}{9.6} & $<0.0001$ \\
\hline & Palpable & 1 & $2.0 \%$ & & \\
\hline$M$ & Negative & 50 & $100.0 \%$ & $\mathrm{~N}$ & $N A$ \\
\hline iviul piry sign & Positive & 0 & $0.0 \%$ & NA & NA \\
\hline
\end{tabular}

\begin{tabular}{|c|c|c|c|c|c|}
\hline & & No. & $\%$ & $\begin{array}{c}\mathrm{Z} \\
\text { Score }\end{array}$ & $\begin{array}{c}\mathbf{p} \\
\text { value }\end{array}$ \\
\hline \multirow[b]{2}{*}{ USG } & Multiple Gallstone & 31 & $62.0 \%$ & \multirow[b]{2}{*}{2.4} & \multirow[b]{2}{*}{0.0164} \\
\hline & Single Gallstone & 19 & $38.0 \%$ & & \\
\hline \multirow{3}{*}{$\begin{array}{l}\text { Operative } \\
\text { Procedure }\end{array}$} & $\begin{array}{c}\text { Laparoscopic } \\
\text { Cholecystectomy }\end{array}$ & 28 & $56.0 \%$ & \multirow{3}{*}{1.4003} & \multirow{3}{*}{0.16152} \\
\hline & $\begin{array}{c}\text { Open } \\
\text { Cholecystectomy }\end{array}$ & 21 & $42.0 \%$ & & \\
\hline & $\begin{array}{c}\text { Open } \\
\text { Cholecystectomy + } \\
\text { CBD Exploration + } \\
\text { T-Tube Insertion } \\
\end{array}$ & 1 & $2.0 \%$ & & \\
\hline \multirow{3}{*}{$\begin{array}{l}\text { Types of } \\
\text { Gallstones }\end{array}$} & Cholesterol & 35 & $70.0 \%$ & \multirow{3}{*}{5.0252} & \multirow{3}{*}{$<0.0001$} \\
\hline & Mixed & 5 & $10.0 \%$ & & \\
\hline & Pigment & 10 & $20.0 \%$ & & \\
\hline \multirow{6}{*}{ Bile C/S } & Citrobacter koseri & 1 & $2.0 \%$ & \multirow{6}{*}{8.427} & \multirow{6}{*}{$<0.0001$} \\
\hline & Escherichia coli & 1 & $2.0 \%$ & & \\
\hline & Klebsiella spp. & 2 & $4.0 \%$ & & \\
\hline & $\begin{array}{l}\text { Staphylococcus } \\
\text { aureus (MRSA) }\end{array}$ & 1 & $2.0 \%$ & & \\
\hline & Pseudomonas SPP. & 1 & $2.0 \%$ & & \\
\hline & No Growth & 44 & $88.0 \%$ & & \\
\hline \multirow{4}{*}{$\begin{array}{c}\text { Gallbladder } \\
\text { Inner Wall } \\
\text { C/S }\end{array}$} & Enterobacter SPP. & 1 & $2.0 \%$ & \multirow{4}{*}{8.0257} & \multirow{4}{*}{$<0.0001$} \\
\hline & Escherichia coli & 3 & $6.0 \%$ & & \\
\hline & Klebsiella spp. & 3 & $6.0 \%$ & & \\
\hline & No Growth & 43 & $86.0 \%$ & & \\
\hline \multirow{4}{*}{$\begin{array}{l}\text { Gallstone } \\
\text { C/S }\end{array}$} & Citrobacter koseri & 1 & $2.0 \%$ & \multirow{4}{*}{8.807} & \multirow{4}{*}{$<0.0001$} \\
\hline & Klebsiella spp. & 2 & $4.0 \%$ & & \\
\hline & Pseudomonas spp. & 1 & $2.0 \%$ & & \\
\hline & No Growth & 46 & $92.0 \%$ & & \\
\hline \multirow{2}{*}{$\begin{array}{l}\text { Culture } \\
\text { Growth }\end{array}$} & Growth & 12 & $24.0 \%$ & \multirow{2}{*}{5.2} & \multirow{2}{*}{$<0.0001$} \\
\hline & No Growth & 38 & $76.0 \%$ & & \\
\hline
\end{tabular}

Table 2. Distribution of USG, Operative Procedure, Types of Gallstones and Culture 


\begin{tabular}{|c|c|c|c|c|c|c|c|c|}
\hline & & No Growth & Growth & Total & Z-Score & P-Value & Chi square & P-Value \\
\hline \multirow{7}{*}{ Types of Gall-Stones } & $\begin{array}{c}\text { Cholesterol } \\
\text { Row\% }\end{array}$ & $\begin{array}{c}32 \\
91.4 \\
84\end{array}$ & $\begin{array}{c}3 \\
8.6 \\
250\end{array}$ & $\begin{array}{c}35 \\
100.0\end{array}$ & 6.9323 & $<0.0001$ & \multirow{7}{*}{21.805} & \multirow{7}{*}{$<0.001$} \\
\hline & Col \% & 84.2 & 25.0 & 70.0 & & & & \\
\hline & $\begin{array}{l}\text { Mixed } \\
\text { Row\% }\end{array}$ & $\begin{array}{c}0 \\
0.0\end{array}$ & $\begin{array}{c}5 \\
100.0\end{array}$ & $\begin{array}{c}5 \\
100.0\end{array}$ & 3.1623 & 0.0015 & & \\
\hline & Col \% & 0.0 & 41.7 & 10.0 & & & & \\
\hline & Pigment & 6 & 4 & 10 & & & & \\
\hline & Row\% & 60.0 & 40.0 & 100.0 & 0.8944 & 0.3734 & & \\
\hline & Col \% & 15.8 & 33.3 & 20.0 & & & & \\
\hline \multirow{6}{*}{ Sex } & Female & 37 & 7 & 44 & & & \multirow{6}{*}{13.16} & \multirow{6}{*}{0.002} \\
\hline & Row\% & 84.1 & 15.9 & 100.0 & 6.396 & $<0.0001$ & & \\
\hline & $\mathrm{Col} \%$ & 97.4 & 58.3 & 88.0 & & & & \\
\hline & Male & 1 & 5 & 6 & & & & \\
\hline & Row\% & 16.7 & 83.3 & 100.0 & 2.3094 & 0.02088 & & \\
\hline & Col \% & 2.6 & 41.7 & 12.0 & & & & \\
\hline \multicolumn{9}{|c|}{ Table 3. Association among Types of Gallstones and Sex vs Culture } \\
\hline
\end{tabular}

\section{DISCUSSION}

Demographically, the present study supports common consensus showing majority of patients being female [88.0\%] with mean age of 40.5 years [ $95 \%, \mathrm{CI}=36.8-44.2 \mathrm{yrs}$.]. The age and sex patterns are commemorative of those said in major literature.

In the present study, cholesterol type of stone was predominant, which was found in $35(70 \%)$ cases out of 50 . Next common gallstone found was pigment type, which was found in $10(20 \%)$ cases out of 50. Mixed type of gallstone was found in 5 cases out of 50. Literature from Shaffer EA 2006, the most common type of stone in developed countries is composed primarily of cholesterol.15 The variation in different types of gallstones varies significantly in different parts of India. Food habits may be one of the main reasons. Cholesterol gallstones are predominant in the Northern, Eastern and Western parts of India, while pigment gallstones are common in the Southern region, [Jayanthi et al, ${ }^{16} \mathrm{M}$. Ashok et al 2003[17]].

In majority of studies, it is found that bile in normal patient is sterile. Csendes $\mathrm{A}$ and $\mathrm{P}$ Burdiles $^{18}$ from Department of Surgery, Santiago, Chile found that no patient had bacteria in bile in control case. Among the 165 with symptomatic gallstone disease $52(32 \%)$ had pathogens in their bile and among the 46 with acute cholecystitis the corresponding figure was 19 (41\%), while among patients with common bile duct stones this figure was 39 (58\%). Among the 58 patients with carcinoma of the gallbladder, the bile grew organism in 47 (81\%). Patients over the age of 60 years tended to be more likely to have organism in their bile than patients aged 60 or less, and the difference was significant for symptomatic gallstone disease. Common bacteria isolated was E. coli $52 \%$.

In a study of $\mathrm{E}$ Hancke, ${ }^{19}$ after cholecystectomy the bacterial content of the bile, gallbladder wall and gallstones was studied in 40 patients. Bacteria could be found in 9 cases in gallbladder wall, in 8 cases in the gallstones and in 3 cases in the bile. In a study by Ballal et al $2001^{20}$ in India, of the 25 gallstones processed, 6 yielded aerobic bacteria (25\%), which were similar to the isolates in bile culture from the same patient.
To conduct the present study- bile, gallbladder inner wall and gallstones were subjected for culture, as only bile culture could not really suggest the presence of bacteria in gallstone which may have initiated lithogenesis due to two fallaciesFirstly, the culture of organism from the bile at time of surgery was not necessarily indicative of cause-effect relation between infective microorganism and lithogenesis, as infection may be secondary to calculus. Secondly, the failure to isolate organism from bile also does not indicate aetiology in lithogenesis unrelated to infection, as it is well known that organism which initiates stone precipitation may not be present in viable form till surgery. So for this, culture of organism from gallstones needs to be done and correlating it with culture of bile for detection of type of micro-organisms.

As the process of gallstone formation is essentially due to biochemical and infective changes and the gallbladder mucosa plays a crucial role in these changes, culture of the mucosa should be a mandatory procedure to determine its role in gallstone formation.

\section{In Present Study, regarding Bile Culture,}

a. Type of infection- Monomicrobial.

b. Total number of positive bile culture- $6(12.0 \%)$ patients out of 50 patients $-3(6.0 \%)$ patients had pigment stones, $2(4.0 \%)$ patients had cholesterol stones and $1(2.0 \%)$ patient had mixed type of stone. The result of present study was similar to study of Ohdan $\mathrm{H}$ et $\mathrm{al}^{21}$ in which maximum bile culture positivity were in pigment stone (65\%). Although in different studies, incidence of positive cases were also seen more in mixed type of gallstone.

c. Most common isolated microorganism- Klebsiella spp. was isolated in 2 samples. Although, Escherichia coli was the commonest organism in various studies.

\section{Regarding the Gallbladder Inner Wall Culture}

a. Type of infection- Monomicrobial.

b. Total number of positive gallbladder inner wall culture- 7 (14.0\%) patients out of $50-4(8.0 \%)$ showed mixed stone, $2(4.0 \%)$ showed pigment stone and $1(2.0 \%)$ had cholesterol stone in their gallbladder.

c. Most frequent isolated organisms- Escherichia coli and Klebsiella spp. (isolated in 3 samples each). 


\section{In the Present Study, regarding Gallstone Culture}

a. Type of infection- Monomicrobial.

b. Total number of positive gallstone culture- 4 (8.0\%) patients out of $50-3(6.0 \%)$ patients had pigment stones and $1(2.0 \%)$ patient had mixed type of stone.

c. Most common isolated organism- Klebsiella spp. was isolated in 2 samples.

Overall, in our Study

a. Total number of patients having no bacterial growth in any sample- 38 (76.0\%) patients, of which $37(74.0 \%)$ were female and $1(2.0 \%)$ was male and $32(64.0 \%)$ patients had cholesterol stones and $6(12.0 \%)$ patients had pigment stones.

b. Total number of patients having bacterial growth in at least one sample- 12 (24.0\%) patients, of which 7 (14.0\%) were female and $5(10.0 \%)$ were male and $5(10.0 \%)$ patients had mixed stones and $4(8.0 \%)$ had pigment stones and $3(6.0 \%)$ had cholesterol stones. Most frequent organisms were Klebsiella spp. and E. coli (growth was in 3 patients each).

c. Total number of patients having bacterial growth in all 3 samples- $2(4.0 \%)$ patients, both were male and both showed growth of Klebsiella spp.

Thus, our study shows that the mixed stones have statistically higher incidence of culture positivity than cholesterol and pigment stones $\left(\chi^{2}=21.8, p<0.001\right)$ and males have significantly higher association with live bacteria than female $\left(\chi^{2}=13.16, p=0.002\right)$.

\section{CONCLUSION}

Infective origin of gallstone disease has long been postulated and various studies to find out infective cause of gallstones have been published. Positive findings were between 3 to $72 \%$, reported in different literatures (Csendes et al 1996a; Csendes et al 1975; Won et al 2008; Mahafzah et al 2009). Most common isolated organism in these studies was Escherichia coli. In our study, we have found positive culture in bile- $12.0 \%$ of cases, gallbladder inner wall- $14.0 \%$ of cases and gallstone- $8.0 \%$ of cases and $24.0 \%$ patients showed positive culture in at least one of three samples. Interestingly, in our study most common organism isolated from bile culture was Klebsiella spp. Surprisingly, in 2 patients we got positive culture in all 3 samples, i.e. bile, gallbladder inner wall and gallstone, which brings us closer to a conclusion that infection has a role of gallstone formation. Not also that in our study, we have got significantly more incidence of infection in male patients. Although to establish this correlation, further long-term study is needed.

The higher incidence of positive culture was found in patients with mixed stones than pigment stones and cholesterol stones, which again supports the long-standing theory of mixed stones formation on dead bacteria nidus. May be scanning electron microscopy would have increased the number of dead bacteria found in the stones.

The knowledge of bacteria helps not only in the knowledge of type of stone, but also it is crucial for proper selection of antimicrobial therapy in a given geographical area.

\section{ACKNOWLEDGEMENT}

We are grateful to Dr. Suman Meyur, Postgraduate Trainee, Department of Radiotherapy, IPGME\&R for his enthusiastic help to analyse the data of this study efficiently.

\section{REFERENCES}

[1] Sun H, Tang H, Jiang S, et al. Gender and metabolic differences of gallstone diseases. World J Gastroenterol 2009;15(15):1886-91.

[2] Doggrell SA. New targets in and potential treatments for cholesterol gallstone disease. Curr Opin Investig Drugs 2006;7(4):344-8.

[3] Everhart JE, Khare M, Hill M, et al. Prevalence and ethnic differences in gallbladder disease in the United States. Gastroenterology 1999;117(3):632-9.

[4] Miquel JF, Covarrubias C, Villaroel L, et al. Genetic epidemiology of cholesterol cholelithiasis among chilean hispanics, amerindians, and maoris. Gastroenterology 1998;115(4):937-46.

[5] Shaffer EA. Epidemiology and risk factors for gallstone disease: has the paradigm changed in the 21st century? Curr Gastroenterol Rep 2005;7(2):132-40.

[6] Xu P, Yin XM, Zhang M, et al. Epidemiology of gallstone in Nanjing City in China. Zhonghua Liu Xing Bing Xue Za Zhi 2004;25(11):928.

[7] Shaffer EA. Gallstone disease: epidemiology of gallbladder stone disease. Best Practice and Research in Clinical Gastroenterology 1920;20(6):981-96.

[8] Wittenburg H, Lammert F. Genetic predisposition to gallbladder stones. Semin Liver Dis 2007;27(1): 109-21.

[9] Moynihan B. Quoted. In: Lard I (edr). A companion in surgical studies E and Livingstone 1958;970.

[10] Hornof R, Pernegger C, Wenzl S, et al. Intraperitoneal cholelithiasis after laparoscopic cholecystectomybehavior of lost concrements and their role in abscess formation. Eur Surg Res 1996;28(3):179-89.

[11] Tzardis PI, Vougiouklakis D, Lymperi M, et al. Septic and other complications resulting from biliary stones placed in the abdominal cavity. Experimental study in rabbits 1996;10(5):533-6.

[12] Zorluoglu A, Ozgue H, Yilmazlar T, et al. Is it necessary to retrieve dropped gallstones during laparoscopic cholecystectomy? Surg Endosc 1997;11(1):64-6.

[13] Maki T. Pathogenesis of calcium bilirubinate gallstone: role of E. coli, ß-glucuronidase and coagulation by inorganic ions, polyelectrolytes and agitation. Ann Surg 1966;164(1):90-100.

[14] Swidsinski A, Ludwig W, Pahlig H, et al. Molecular genetic evidence of bacterial colonization of cholesterol gallstones. Gastroenterology 1995;108(3):860-4.

[15] Shaffer EA. Gallstone disease: epidemiology of gallbladder stone disease. Best Pract Res Clin Gastroenterol 2006;20(6):981-96.

[16] Jayanthi V. Pattern of gall stone disease in Madras city south India, a hospital based survey. J Associated phys India 1996;44(7):461-4. 
[17] Ashok M, Rautray TR, Nayak PK, et al. Energy dispersive X-ray fluorescence analysis of gallstones. Radioanal Nucl Chem 2003;257(2):333-5.

[18] Csendes A, Becerra M, Burdiles P, et al. Bacteriological studies of bile from gallbladder in patients with carcinoma of the gallbladder, cholelithiasis, common bile duct stones and no gallstones disease. Eur J Surg 1994;160(6-7):363-7.

[19] Hancke E, Nusche A, Marklein G. Bacteria in the gallbladder wall and gallstones--indications for cholecystectomy. Langenbecks Arch Chir 1986;368(4):249-54.
[20] Ballal M, Jyothi KN, Antony B, et al. Bacteriological spectrum of cholecystitis and its antibiogram. Indian Journal of Medical Microbiology 2001;19(4):212-4.

[21] Ohdan H, Oshiro H, Yamamoto Y, et al. Bacteriological investigation of bile in patients with cholelithiasis. Springer 1993;23(5):390-5. 